
\title{
28 Research Square \\ Identifying a new therapeutic target for bone metastasis of breast cancer
}

\author{
Xiaoyan Chen \\ Xiaoxing Shi \\ Yiwen Liu \\ Yiqing He \\ Yan Du \\ Guoliang Zhang \\ Cuixia Yang \\ Feng Gao
}

\section{Video Byte}

Keywords: Hyaluronan, mammary tumour, bone metastasis, bone marrow stromal cells, bone marrow, breast cancer, metastasis, cancer, Cell Communication and Signaling

Posted Date: October 30th, 2020

DOl: https://doi.org/10.21203/rs.3.rs-100911/v1

License: (c) (i) This work is licensed under a Creative Commons Attribution 4.0 International License. Read Full License 


\section{Abstract}

Breast cancer is the most common cancer in women worldwide. Although at earlier stages it is treatable, breast cancer becomes incurable when cancer cells migrate to the bone. Understanding how breast cancer cells metastasize to the bone could reveal new therapeutic targets. New research reports the role of a bone marrow component in mediating breast cancer metastasis and malignancy. Hyaluronan (HA) is an abundant component of the bone marrow (BM) extracellular matrix. Dysregulated HA metabolism plays a role in other cancers, including acute myeloid leukemia, but whether this effect exists in breast cancer is unknown. Researchers used a mouse model to evaluate HA remodeling in tumor-associated bone marrow. They found that cancer cell malignancy was correlated with HA accumulation in the bone marrow. Stromal cell-derived HA promoted breast cancer cell growth and accelerated bone destruction. These pro-cancer activities were mediated by the receptor CD44 and signaling pathways including PI3K, Cyclin D1, and CDK4. Although clinical research is needed to evaluate these pathways in humans, the results suggest that stromal HA may be an ideal new target to treat bone metastasis in advanced breast cancer. 